\title{
Evaluation of human first trimester decidual and telomerase-transformed endometrial stromal cells as model systems of in vitro decidualization
}

\author{
Leila Saleh', Gerlinde R Otti ${ }^{1}$, Christian Fiala², Jürgen Pollheimer ${ }^{1}$ and Martin Knöfler ${ }^{1 *}$
}

\begin{abstract}
Background: Decidualization, the differentiation process of maternal uterine stromal cells into secretory decidual cells, is a prerequisite for successful implantation and progression of pregnancy. For in vitro differentiation mostly primary human endometrial stromal cells (HESC) isolated from uterine samples after hysterectomy for benign gynaecological diseases are utilised. However, a continuous supply of endometrial tissue is often lacking. Hence, we analysed whether cultivated human decidual stromal cells (HDSC) prepared from first trimester pregnancy terminations may represent an alternative model system for in vitro decidualization. Moreover, based on the expression of critical marker genes these cells were compared to a previously established endometrial stromal cell line during in vitro differentiation.
\end{abstract}

Methods: HDSC isolated from decidual tissue attached to first trimester placentae, and telomerase-transformed human endometrial stromal cells (THESC) were characterised by immunofluorescence and differentiated in vitro using either cyclic adenosine monophosphate (CAMP) and/or estrogen (E2)/progesterone (P4). Proliferation was measured by analyzing cumulative cell numbers. Expression of mRNAs encoding progesterone receptor (PR), prolactin (PRL), insulin-like growth factor binding protein-1 (IGFBP1), and Dickkopf-1 (DKK1) was evaluated using quantitative PCR after 3,6,9 and 12 days of in vitro differentiation. PRL and IGFBP-1 protein expression was investigated by enzyme-linked immunosorbent assay (ELISA) and Western blotting, respectively. Furthermore, forkhead box O1A (FOXO1A), a critical transcription factor in decidualization, was analysed by immunofluorescence and Western blotting at two different time points of differentiation.

Results: Treatment with CAMP provoked morphological changes and growth arrest of THESC and HDSC, the latter showing loss of cells after 6 days of treatment. E2P4 stimulation did neither affect cell morphology nor proliferation of THESC and HDSC. Upon CAMP stimulation PR mRNA was suppressed in HDSC but not in THESC, whereas E2P4 did not alter transcript levels in both cell types. Protein expression of PR-A and PR-B was detectable in HDSC and diminished under CAMP, whereas THESC failed to produce the nuclear receptors. Supplementation of CAMP induced mRNA and protein expression of PRL and IGFBP-1 in both cell types at day 3, 6, 9, and 12 of treatment. In HDSC stimulation with E2P4 increased PRL and IGFBP-1 mRNA and protein production, whereas hormone treatment did not induce the two factors in THESC. E2P4 increased DKK1 mRNA at all time points in HDSC and CAMP provoked induction at day 9 and 12 of differentiation. In contrast, CAMP suppressed DKK1 mRNA in THESC, whereas E2P4 was ineffective. In both cell types combined treatments with cAMP and E2P4 provoked higher expression levels of PRL and IGFBP1 mRNA and protein as compared to CAMP stimulation alone. FOXO1A protein and its nuclear abundance were increased by CAMP in both cell types. However, reduction of its nuclear localisation upon E2P4 treatment could only be observed in HDSC.

\footnotetext{
* Correspondence: martin.knoefler@meduniwien.ac.at 'Department of Obstetrics and Fetal-Maternal Medicine, Reproductive Biology Unit, Medical University of Vienna, A-1090 Vienna, Austria Full list of author information is available at the end of the article
} 
Conclusion: Both HDSC and THESC may represent suitable model systems for CAMP-dependent in vitro decidualization. Since cAMP decreases cell viability of HDSC after 6 days of incubation, this substance should be preferentially used in short-term experiments. Progesterone treatment of THESC might not be applicable since these cells lack progesterone response and PR protein. In contrast, stimulation of PR-expressing HDSC with E2P4 or CAMP/E2P4 may represent an appropriate protocol for human in vitro decidualization inducing and maintaining expression of critical marker genes in a time-dependent manner.

\section{Background}

Differentiation of estrogen-primed, uterine stromal cells into stromal cells of pregnancy, termed decidualization, starts in the secretory phase of the menstrual cycle due to rising progesterone levels. In humans the process occurs independently of an implanting blastocyst but is only maintained upon pregnancy, since absence of a conceptus provokes shedding of the decidualized endometrial layer and menstruation. Decidualization involves profound changes in cellular function, morphology and gene expression. Typically, spindle-shaped uterine stromal cells transform into polygonal, epithelial-like decidual cells producing characteristic hormones, growth factors and cytokines such as PRL [1], tissue factor [2], IGFBP1 [3], interleukin (IL)-15 [4] or IL-11 [5]. Secreted factors of the decidua are thought to fulfil numerous functions in pregnancy such as regulation of placental trophoblast implantation and invasion, recruitment and differentiation of uterine natural killer (NK) cells and protection against immune-mediated damage or oxidative stress [6-8]. Moreover, decidual stromal cells actively participate in remodelling of the extracellular matrix of the uterus by expressing diverse extracellular matrix (ECM)-proteins such as collagen IV, fibronectin, laminin and alpha smooth-muscle actin, the latter provoking myofibroblast-like properties of the cells $[9,10]$. The crucial role of decidual cells in pregnancy is further emphasized by the fact that gene knock-out of different decidual proteins in mice caused failures in implantation, infertility or intrauterine lethality [11].

Although the molecular mechanisms of decidualization are still poorly understood, various critical factors controlling differentiation and decidua-specific hormone expression have been unravelled. Transcription factors such as HoxA-10, HoxA-11, FOXO1A, Stat5 and C/ EBP $\beta$ were shown to control promoter activity of decidual PRL and/or IGFBP1 in a differentiation-dependent manner [12]. Moreover, steroid hormones and their nuclear receptors, estrogen receptor (ER) and PR, play a pivotal role in decidual differentiation, since lack of these genes impairs implantation and decidualization [8]. Accordingly, progesterone is thought to be necessary to maintain the decidualized phenotype of the estrogenprimed endometrium. However, progesterone alone is a weak inducer of decidualization in primary HESC and the combined action of progesterone and cAMP is required for maximal and sustained expression of decidual marker genes [12]. For example, the decidual prolactin promoter lacking a palindromic PR recognition sequence, can only be stimulated with progesterone when cultures were pre-treated with exogenous cAMP suggesting that activation of the proteinkinase A pathway may enhance the transcriptional activity of PR through modification of PR and its co-activators [13]. Critical ligands such as relaxin, prostaglandin E2 or gonadotrophins are thought to activate cAMP-dependent signalling in these cells [14]. On the other hand, progesterone treatment provokes elevation of endogenous cAMP levels in decidualizing stromal cells [15] suggesting complex cross-talk between the two signalling pathways.

Given the fact that cAMP and steroid hormones are critically involved in uterine stromal cell differentiation, numerous protocols using exogenous cAMP analogues and/or estrogen/progestational hormones, such as $\mathrm{P} 4$ or medroxyprogesterone acetate (MPA) in vitro have been developed [14]. As cellular model for human in vitro decidualization HESC, which have been isolated from uterine samples and biopsies after hysterectomy for benign gynaecological conditions, such as myomas, or patients undergoing tubal ligation, are widely utilised $[16,17]$. However, availability of physiological, endometrial tissue might be limited provoking the need for alternative sources and model systems. Indeed, different cell lines have been developed which can be utilised for cAMP-dependent differentiation but often lack P4 responsiveness $[18,19]$. Hence, we herein analysed stromal cells which have been isolated from decidual tissue of first trimester pregnancy terminations as a possible model system of cAMP and/or E2P4-induced decidualization. Moreover, a commonly used, telomerase-transformed cell line, THESC [20], was investigated in parallel with respect to cAMP/steroid hormone-dependent differentiation and expression of decidual marker genes.

\section{Methods}

\section{Isolation and cultivation of primary human decidual} stromal cells

Decidual specimen were obtained from legal abortions of healthy first trimester pregnancies (between $8^{\text {th }}$ and 
$11^{\text {th }}$ week of gestation, $\mathrm{n}=13$ ) with the permission of the ethical committee of the Medical University of Vienna. After separation of decidual tissues from the placenta, samples were washed in phosphate buffered saline to remove blood clots and subsequently minced in $3 \mathrm{~mm}^{3}$ pieces in a small volume of Hank's balanced salt solution (HBSS, Sigma-Aldrich, St. Louis, MO). Tissue fragments were collected in a T-75 cell culture flask and covered with $50 \mathrm{ml}$ digestion solution. Primary human decidual stromal cells were prepared by enzymatic dispersion using $2 \mathrm{mg} / \mathrm{ml}$ collagenase I (484 IU/ $\mathrm{ml}$, Invitrogen, Paisly, UK) and $0.5 \mathrm{mg} / \mathrm{ml}$ DNAse I (Sigma-Aldrich) in HBSS containing $25 \mathrm{mM}$ HEPES. After digestion $\left(60\right.$ minutes at $\left.37^{\circ} \mathrm{C}\right)$ in a shaking water bath, supernatant containing dispersed cells was filtered through a $70 \mu \mathrm{m}$ nylon mesh (BD Biosciences, Bedford, UK) to remove larger tissue fragments. Residual undigested tissue was further incubated for 60 minutes in 25 $\mathrm{ml}$ of digestion solution. Subsequently, supernatants were pooled, centrifuged at $1000 \mathrm{rpm}$ for 5 minutes and pellets were washed twice in HBSS. Isolated cells were seeded in phenolred-free DMEM/F12 medium (Invitrogen) supplemented with $10 \%$ heat-inactivated fetal bovine serum (PAA Laboratories $\mathrm{GmbH}$, PaschingAustria), 1\% ITS + Premix (BD Biosciences), and $50 \mu \mathrm{g} / \mathrm{ml}$ Gentamicin (Invitrogen) and cultivated at $37^{\circ} \mathrm{C}, 5 \% \mathrm{CO}_{2}$ and $95 \%$ humidity. Purity of HDSC was routinely examined by immunofluorescence using antibodies against vimentin and cytokeratin 7 detecting stromal, epithelial and endothelial cells, respectively (see below). Cultures were negative for CD31 ( $1 \mu \mathrm{g} / \mathrm{ml}$; Abcam, Cambridge, UK), HUVEC were used as a positive control.

\section{Re-decidualization of primary human decidual stromal cells}

For in vitro decidualization isolated HDSC were utilized between passage three and five. Briefly, cells were confluently seeded in 24-well plates $\left(2.5 \times 10^{5} / \mathrm{cm}^{2}\right)$ and stimulated on the next day with $0.5 \mathrm{mM} 8$-Bromo-cAMP (Sigma-Aldrich) and/or $10 \mathrm{nM}$ estrogen (E2; $17 \beta$-estradiol-acetate; Sigma-Aldrich)/1 $\mu \mathrm{M}$ progesterone (P4; 4pregnene-3,20-dione; Sigma-Aldrich) for 3, 6, 9 and 12 days. HDSC kept under the same culture conditions but without addition of cAMP or E2P4 served as non-stimulated controls. Every third day medium was changed and stimuli were refreshed. Supernatants were collected, immediately frozen in liquid nitrogen and stored at $-80^{\circ}$ $\mathrm{C}$ for further analyses. Morphological changes were daily monitored with a phase contrast microscope and photographs were taken using a digital camera (C-4040 Zoom, Olympus, Vienna, Austria) for documentation. In addition, total protein and RNA were extracted from decidualizing cultures or non-stimulated controls at indicated time points.

\section{Cultivation and decidualization of THESC}

The telomerase-immortalised endometrial stromal cell line THESC [20] was purchased from American Type Culture Collection (CRL-4003; Wesel, Germany) and cultivated as described by the supplier. Briefly, cells were cultured in phenol red-free DMEM/F12 medium (Invitrogen) supplemented with 10\% heat-inactivated fetal bovine serum (PAA Laboratories GmbH), 1\% ITS+ Premix (BD Biosciences) and puromycin $(5 \mu \mathrm{g} / \mu \mathrm{l}$; Invitrogen). In vitro decidualization of THESC was performed as described above for HDSC.

Immunofluorescence of decidual tissue and cultured cells First trimester decidual tissues $\left(\mathrm{n}=3\right.$ between $8^{\text {th }}$ and $10^{\text {th }}$ week) were washed with phosphate buffered saline (PBS) and fixed for at least 4 hours in $4 \%$ paraformaldehyde. After embedding serial sections $(3 \mu \mathrm{m})$ were prepared on a Microm HM 355S microtome and mounted on silanized microscope slides. Subsequently, slides were dried for 15 minutes at $55^{\circ} \mathrm{C}$ and dewaxed in xylol for 10 minutes. Finally sections were slowly rehydrated in decreasing concentrations of ethanol (100\%, 96\% and $70 \%)$ and gathered in deionised water. Antigen retrieval was performed using $0.05 \%$ citraconic anhydride solution pH 7.0 (Thermo Fisher Scientific, Waltham, MA) at $98^{\circ} \mathrm{C}$ for 20 minutes. Slides were allowed to cool down for 30 minutes at room temperature before they were washed three times with PBS and clamped with plastic cover slips (Shandon, Frankfurt, Germany). Unspecific binding sites were blocked with $100 \mu \mathrm{l}$ 0.05\% fish skin gelatin from cold water fish (Sigma-Aldrich)/PBS for 30 minutes at room temperature and $100 \mu \mathrm{l}$ primary antibodies diluted in blocking solution were administered. After overnight incubation at $4{ }^{\circ} \mathrm{C}$ slides were washed (100 mM TrisCl pH 7.5, 50 mM NaCl, 0.05\% Tween20) and covered with $100 \mu \mathrm{l}$ secondary antibodies diluted in blocking buffer. After one hour sections were washed again and counterstained with $100 \mu \mathrm{l}$ DAPI (Roche Diagnostics GmbH, Vienna, Austria) diluted 1:1000 in PBS for 10 minutes. After a final washing step, slides were removed from the staining chamber and mounted with Fluoromount-G (Southern Biotechnology, Birmingham, UK). Sections were dried overnight and subsequently analysed by fluorescence microscopy using a BX 50 Microscope (Olympus). For immunofluorescence of HDSC and THESC, cells were seeded on 8-well chamber slides, fixed with $4 \%$ paraformaldehyde for $10 \mathrm{~min}$ utes, washed, and permeabilized with $0.1 \%$ Triton-X 100 (Sigma-Aldrich) for 5 minutes. Blocking, incubation with primary and secondary antibodies and counterstaining with DAPI were done as described above. The following primary and secondary antibodies were used: mouse anti-human cytokeratin 7, OV-TL12/30, Dako, 1:100; rabbit anti-human vimentin, $\mathrm{H}-84$, Santa Cruz 
Biotech. 1:100; rabbit anti-human FOXO1A, C29H4, Cell Signaling Technology, Danvers, MA, 1:100; goatanti-mouse Alexa Fluor 488, goat-anti-rabbit Alexa Fluor 568 or goat-anti-rabbit Alexa Fluor 488. All secondary antibodies were diluted 1:500. Analysis of signals was carried out by fluorescence microscopy (Olympus BX50) and digitally photographed. To determine FOXO1A protein expression digital images (four different fields for each condition) were counted using Cell^ $\mathrm{P}$ Soft Imaging System (Olympus). Subsequently the ratio of FOXO1A-positive nuclei to DAPI-stained nuclei was calculated.

\section{Proliferation assay}

To assess proliferation during decidualization cumulative cell numbers were measured. Primary HDSC and THESC were confluently seeded in duplicates $(2.5 \times$ $10^{5} / \mathrm{cm}^{2} ; 12$-well plates), respectively. On the next day cultures were stimulated with cAMP or E2P4. Subsequently, cultures were trypsinized after 3, 6, 9 and 12 additional days and cell numbers were counted using a CASY Cell Counter (Schärfer System, Reutlingen, Germany).

\section{RNA extraction and quantitative real-time PCR}

Total RNA was extracted by direct lysis in the culture dishes using TriFast Reagent (PeqLab, Erlangen, D) according to the manufacturer's instructions. RNA amount and integrity were evaluated using the Agilent Bioanalyzer 2100 (Agilent, Palo Alto, CA). 2 нg RNA were reverse transcribed using 200U of RevertAid $\mathrm{H}$ Minus M.MuLV Reverse Transcriptase (Fermentas, St. Leon-Rot, D), $0.2 \mu \mathrm{g}$ Hexanucleotide Mix (Roche Diagnostics $\mathrm{GmbH}$, Vienna, Austria), $0.5 \mu \mathrm{l}$ RaseOUT (Recombinant Ribonuclease Inhibitor, Invitrogen) and $0.5 \mathrm{mM}$ dNTP (Promega, Madison, WI) in final volume of $20 \mu \mathrm{l}$. Quantitative real-time PCR was performed on the ABI 5700 Sequence Detection System (Applied Biosystems, Carlsbad, CA) using Taq Man Gene Expression Assays (TaqMan Universal PCR Master Mix, 20× Taq Man Gene Expression Assay Mix form PRL (Hs 00168730_m1), IGFBP1 (Hs 00426285_m1), DKK1 (Hs 0018740_m1), PR (Hs01556707_m1) and TATA-box binding protein (TBP; TaqMan endogenous control) according to the manufacturer's instructions. Calculation of signals was done as suggested in the PE Biosystems Sequence Detector User Bulletin and elsewhere [21]. Briefly, threshold cycle $(\mathrm{Ct})$ is defined as the first fluorescent signal reaching statistical significance above background. For each individual condition, normalisation to $\mathrm{Ct}$ values of the house keeping gene (TBP) was performed (calculation of $\Delta \mathrm{Ct}$ values). Subsequently, relative expression levels were evaluated by using transcript levels of unstimulated controls of day 3 as calibrator $(\Delta \Delta \mathrm{Ct})$.

\section{Protein extraction and Western blot analyses}

Isolation of total cellular protein was performed by freezing (liquid nitrogen)-thawing in a buffer containing $50 \mathrm{mM}$ Tris- $\mathrm{HCl}, 125 \mathrm{mM} \mathrm{NaCl}, 0,1 \% \mathrm{NP}-40,5 \mathrm{mM}$ EDTA, $50 \mathrm{mM} \mathrm{NaF}, 1 \mathrm{mM}$ DTT, protease inhibitor cocktail 1:100 and HALT Phosphatase Inhibitor Cocktail 1:100 (Pierce, Rockford, IL). Nuclear/cytoplasmic extracts were prepared using NE-PER nuclear and cytoplasmic extraction reagent according to the manufacturer's instructions (Pierce, Rockford, IL). For detection of PR or FOXO1A protein expression equal amounts $(20 \mu \mathrm{g})$ of total or nuclear protein measured by Bradford assay (Bio-Rad Laboratories, Hercules, CA) were separated on $8.5 \%(\mathrm{PR})$ or $10 \%$ (FOXO1A) SDS/polyacrylamide gels. For analyses of IGFBP1 concentrations in supernatants ( $1 \mathrm{ml}$ aspirated from 12 wells) sample preparation was performed under non-reducing conditions. Volumes were normalised to the respective cell numbers measured with Casy Cell Counter, adjusted to $20 \mu \mathrm{l}$ with culture medium and $20 \mu \mathrm{l}$ of $2 \times$ Novex Tris-Glycine Sample Buffer (Invitrogen, Carlsbad, CA) were added. After incubation for 10 minutes at room temperature, samples were loaded onto $12.5 \%$ SDS/polyacrylamide gels. After separation proteins were transferred onto methanol-activated polyvinyliden difluoride (PVDF) membranes (Amersham, Buckinghamshire, UK) in a buffer containing $25 \mathrm{mM}$ Tris.Cl, pH 8.3, 0,5\% SDS, 192 mM glycine, 20\% methanol. Subsequently PVDF membranes were blocked with $5 \%$ non-fat dry milk/Tris-buffered Saline-Tween 20 (TBS-T) for 60 minutes at room temperature to eliminate unspecific binding and incubated overnight with primary antibodies in $0.5 \%$ non-fat dry milk/TBS-T at $4^{\circ} \mathrm{C}$ as described [21]. The following primary antibodies were used: mouse anti-human IGFBP1 $(1 \mu \mathrm{g} / \mathrm{ml}$ clone 33627; R\&D Systems, Minneapolis, MN); rabbit anti-human PR (1:1000; Cell Signaling Technology); rabbit anti-human FOXO1A (1:1000, C29H4, Cell Signaling Technology). PVDF membranes were washed three times for 5 minutes in $1 \times$ TBS-T and subsequently treated with secondary anti-mouse or anti-rabbit horseradish peroxidase-linked antibodies (anti-mouse IgG, Sigma; anti-rabbit IgG, Amersham; both diluted 1:50.000 in 0.5\% non-fat dry milk/TBS-T). After one hour of incubation at room temperature blots were rinsed three times for 5 minutes and signals were developed by using ECL Plus Western blotting detection system according to the manufacturer's instruction (Amersham). Finally membranes were exposed to autoradiography for visualization of signals. Antibodies binding IGFBP1, FOXO1A, PR-A and PR-B detected specific signals at $32 \mathrm{kD}, 78 \mathrm{kD}, 90 \mathrm{kD}$, and $118 \mathrm{kD}$, respectively. For positive control of PR protein expression total protein lysates of the breast cancer cell line T47D were utilised. To monitor equal protein loading of 
cellular extracts, blots were again washed three times with 1 xTBS-T for 10 minutes, blocked in $5 \%$ non-fat dry milk for 60 minutes and incubated with rabbit antihuman GAPDH antibody (1:1000; Cell Signaling Technology) or mouse anti-human TopolI $\beta$ antibodies $(0.25$ $\mathrm{mg} / \mathrm{ml}$; BD Biosciences, normalization of nuclear protein extracts) over night at $4^{\circ} \mathrm{C}$. GAPDH $(37 \mathrm{kD})$ was detectable both in cytoplasmic and nuclear fractions as recently shown [22], whereas TopoII $\beta$ (180 kD) was exclusively found in the nucleus.

\section{Prolactin ELISA}

Secreted PRL was measured in culture supernatants using a PRL ELISA according to the manufacturer's instructions (Alpco, Salem, NH) and normalised to cell numbers. Intra-assay precision levels indicated by the coefficient to variation ranged between $2.1 \%$ and $4.6 \%$ and inter-assay precision levels between $3.1 \%$ and $5.4 \%$; sensitivity was $2 \mathrm{ng} / \mathrm{ml}$.

\section{Statistical analysis}

For comparison of two conditions of interest statistical analyses were performed with Student's paired T-test or Mann-Whitney U test using SPSS 14 (SPSS Inc., Chicago, IL). Gaussian distribution and equality of variances were examined with Kolmogorov-Smirnov test and Levene's test, respectively. A T-test p-value of $<0.05$ was considered statistically significant.

\section{Results}

Morphological characterization and proliferation of HDSC and THESC upon in vitro differentiation

Decidual tissue attached to first trimester placentae, purified HDSC and THESC were analysed with respect to epithelial and stromal cell content using immunofluorescence (Figure 1A). Sections of embedded, decidual tissue showed vimentin and cytokeratin 7 expressions in stromal cells and residual glands, respectively. Primary HDSC characterized at passage 3
A
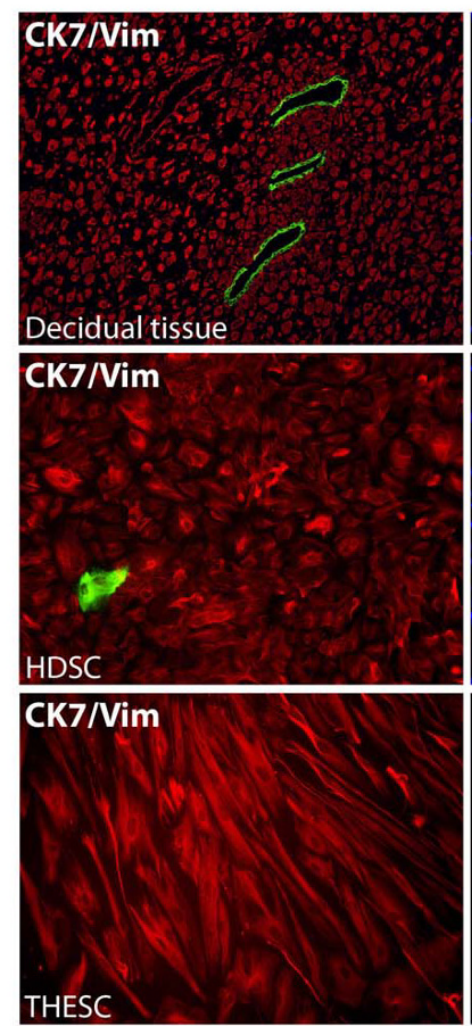

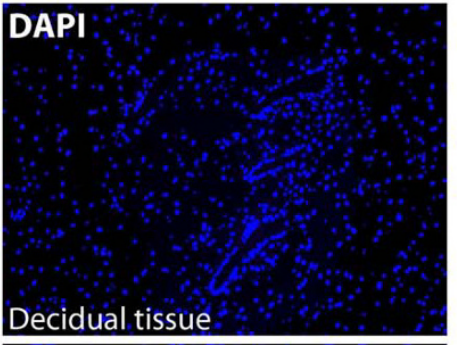

DAPI
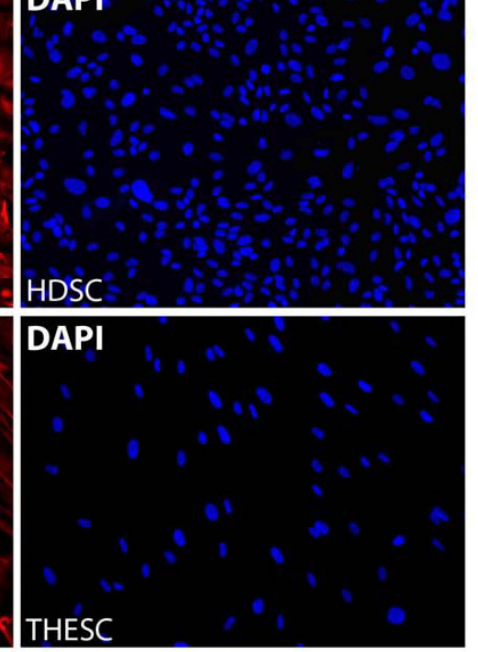

B
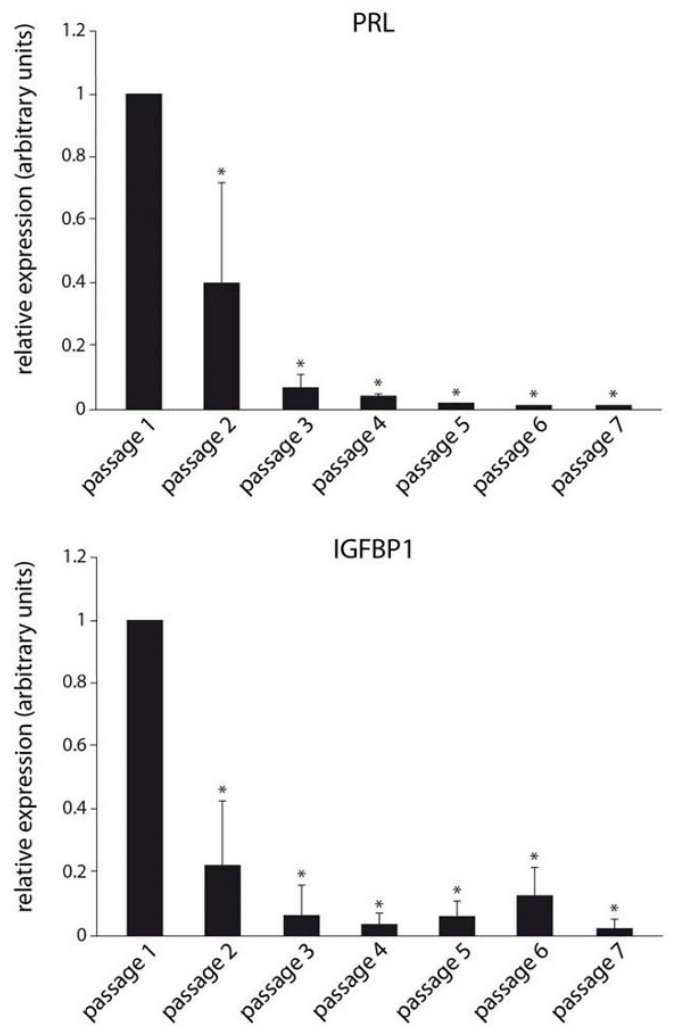

Figure 1 Characterization of first trimester decidual tissue, primary HDSC and THESC using immunofluorescence and quantitative realtime PCR. Preparation of tissue sections, isolation of primary HDSC, cultivation of THESC and quantitative real-time PCR were performed as described in Materials and Methods. A) Immunofluorescence of decidual cells and tissue. First trimester decidual tissue isolated at $10^{\text {th }}$ weeks of pregnancy, primary human decidual stromal cells at passage 3, and THESC are depicted. Double immunofluorescence staining with antibodies recognizing vimentin (red) and cytokeratin 7 (green) to detect stromal or epithelial cells, respectively, are shown. The respective counterstainings of tissues and cultures with DAPI are depicted on the right hand side. Representative pictures were taken at a 100-fold (decidual tissue) and 200fold (cultivated cells) magnification, respectively. B) Quantitative real-time PCR measuring basal PRL and IGFBP1 mRNA expression in HDSC in a passage-dependent manner. For normalization values at passage 1 were arbitrarily set at 1 . Bars represent mean values \pm S.D. of four different experiments performed in duplicates. ${ }^{*}$ indicates $p<0.05$ compared to passage 1. 
contained mostly vimentin-positive cells with a small numbers of cytokeratin 7-positive, contaminating epithelial cells $(0.83 \% \pm 0.38$ S.D., $n=6)$ whereas $100 \%$ of THESC expressed vimentin. Since HDSC were derived from early pregnancy decidua, cultures might already express elevated levels of decidua-specific proteins. Hence, to determine the optimal time point for in vitro re-decidualization basal mRNA expression of decidual marker genes was analysed in a passage-dependent manner. Quantitative real-time PCR revealed residual PRL and IGFBP1 mRNA levels in the early passages 1 and 2 which dropped upon further cultivation (Figure 1B). Therefore, in vitro differentiation was routinely performed with cultures at passage 3 to 5 . Subsequently, morphological changes and proliferation of in vitro decidualizing cultures were assessed (Figure 2). Compared to THESC showing a spindle-shaped, fibroblastoid morphology, areas with cells displaying a cobblestonelike morphology were observed in untreated HDSC (Figure 2A). Stimulation with cAMP strongly induced the polygonal phenotype (Figure $2 \mathrm{~A}$ ) and provoked growth arrest in both cell types (Figure 2B). Long-term treatment with cAMP additionally reduced viability of HDSC since compared to controls cell numbers significantly decreased from day 6 onwards. In contrast, loss of cell numbers could not be observed in cAMP-treated THESC. Stimulation with E2P4 did not induce morphological changes in HDSC or THESC (Figure 2A). Proliferation of both cell types was not affected upon hormone treatment (Figure 2B).

\section{Differentiation-dependent expression of progesterone receptors in HDSC and THESC}

Expression of PR was analysed in cAMP and/or E2P4 treated HDSC and THESC (Figure 3). Quantitative realtime PCR revealed that cAMP significantly decreased PR mRNA in HDSC at the different time points, whereas E2P4 did not affect transcript levels (Figure 3A). Surprisingly, considerable, constitutive expression of PR mRNA was detectable in THESC, but in contrast to HDSC cAMP did not alter transcript levels (Figure $3 \mathrm{~A})$. Western blot analyses showed that HDSC also produced the PR proteins, PR-A (90 kD) and PR-B (118 $\mathrm{kD}$ ), which were identified by using the PR-expressing breast cancer cell line T47D [23] as a positive control (Figure 3B). Both isoforms were suppressed in the
A

HDSC
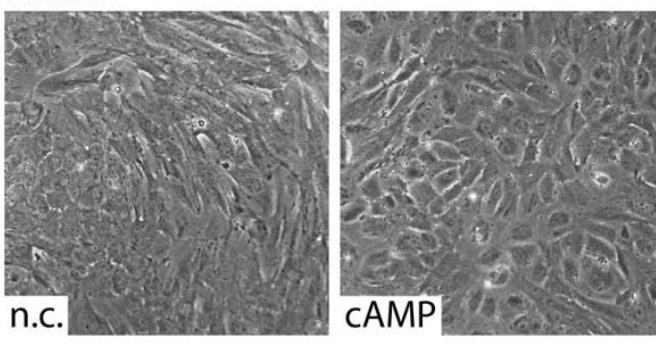

\section{THESC}
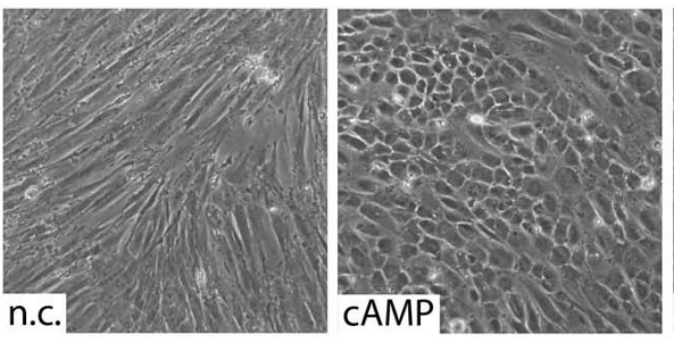
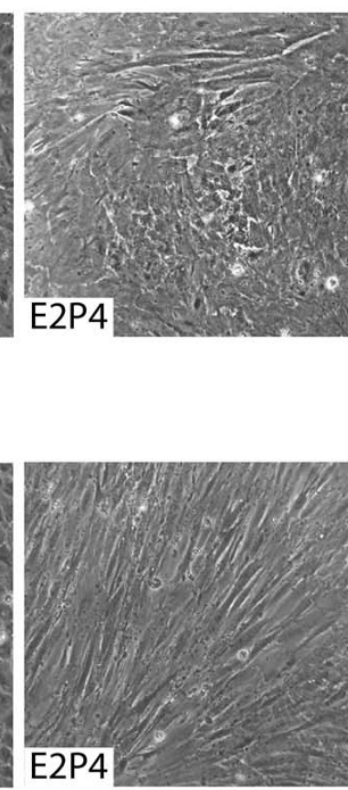

B
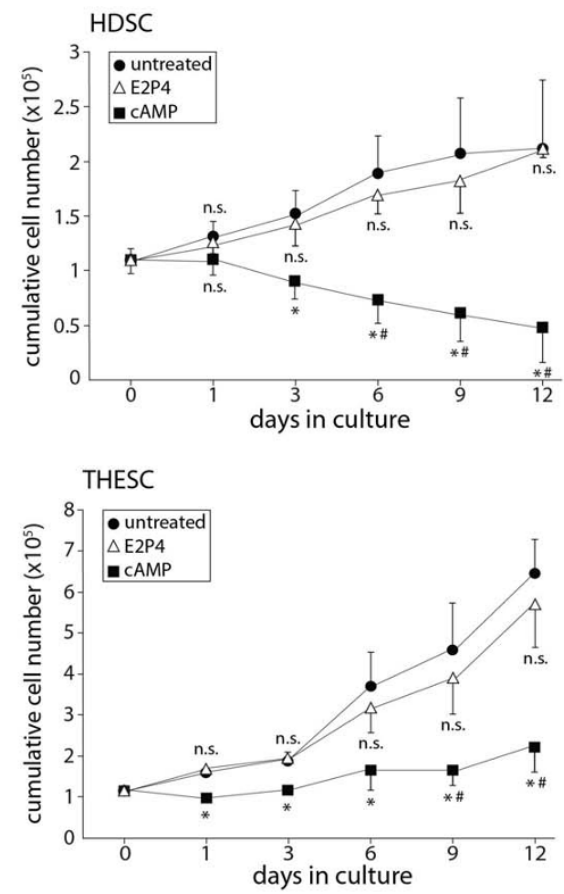

Figure 2 Morphological differentiation and proliferation of HDSC and THESC in the absence or presence of CAMP or E2P4. Cultivation, in vitro decidualization and proliferation assays of HDSC and THESC were performed as described above. A) Morphological characteristics of untreated and CAMP or E2P4-stimulated HDSC and THESC at day 6 of in vitro differentiation. Representative pictures at a 100-fold magnification are shown. B) Proliferation of HDSC and THESC in the absence or presence of CAMP or E2P4. Cumulative cell numbers of each cultures system $(n=4)$ were measured in duplicates at $1,3,6,9$, and 12 days of in vitro decidualization. ${ }^{*}$ indicates $p<0.05$ compared to negative control (n.c.) of the same day; \# indicates $p<0.05$ compared to n.c. of day 0; n.s., not significant compared to n.c. of the same day. 
A
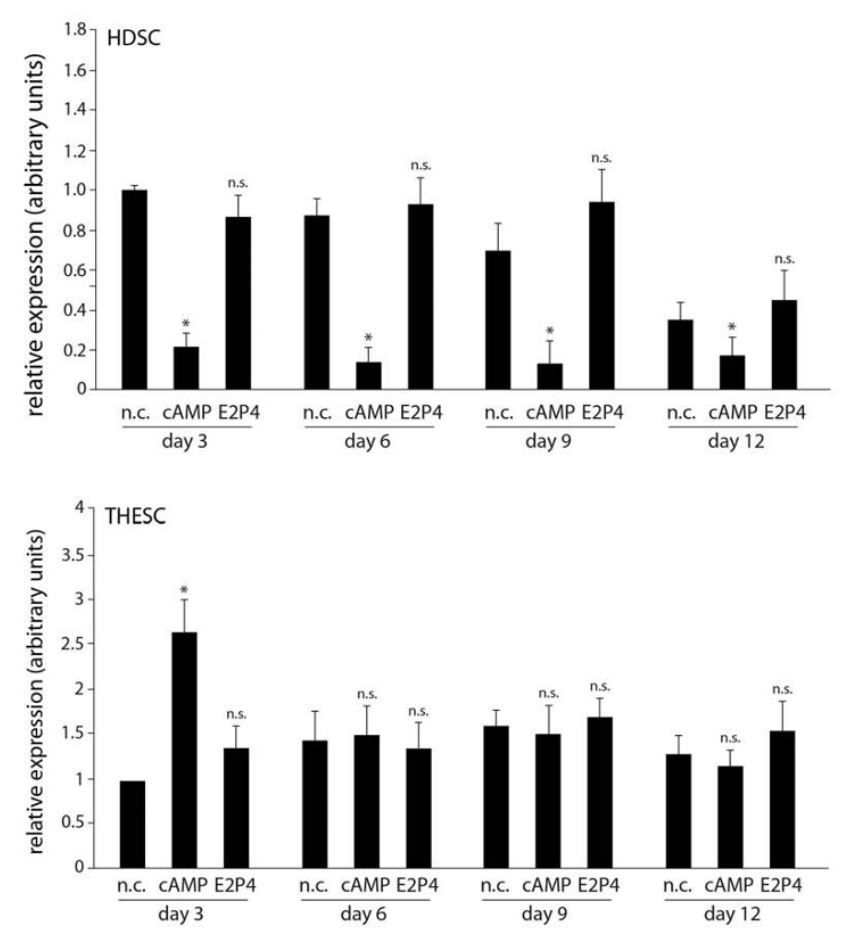

B

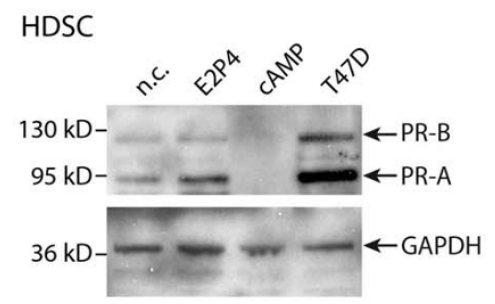

C

THESC

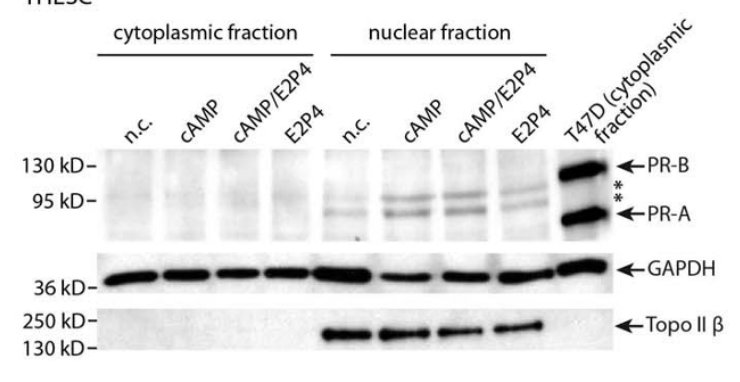

Figure 3 Expression analyses of PR in differentiating HDSC and THESC. Quantitative real-time PCR and Western blot analyses were performed as described in Materials and Methods. Representative examples of Western blots are shown. A) PR mRNA expression at day 3, 6, 9, and 12 of CAMP or E2P4 stimulation. For relative quantification of total PR mRNA expression, n.c. of day three was arbitrarily set at 1 (calibrator). Bars indicate mean values \pm SEM of seven and five different experiments performed in HDSC and THESC, respectively. PCR reactions were done in duplicates. * indicates $p<0.05$ compared to the n.c. of the same day; n.s., not significant. B) Western blot analyses showing PR protein expression in total cellular extracts of dezidualizing HDSC. Specific signals detecting PR-A ( $90 \mathrm{kD})$ and PR-B (118 kD) in the absence or presence of CAMP or E2P4 (day 9) are depicted. Total extracts prepared from T47D cells were used as a positive control. Marker bands are indicated on the left. GAPDH was used as a loading control. C) Western blot analyses of cytoplasmic and nuclear extracts isolated from unstimulated and differentiated THESC which had been treated with CAMP and/or E2P4 for 9 days. Specific signals detecting PR-A (90 kD) and PR-B (118 kD) in T47D are depicted. Marker bands are indicated on the left and unspecific signals are indicated by stars. GAPDH and Topoll $\beta$ were used as loading controls for cytoplasmic and nuclear extracts, respectively.

presence of cAMP (day 9 of differentiation), but did not change upon E2P4 treatment. However, the PR antibody specifically recognizing PR-A and PR-B in HDSC and T47D cells failed to detect correct signals in cytoplasmic and nuclear extracts of THESC in the absence or presence of cAMP and/or E2P4 (Figure 3C).

\section{Expression of decidual marker genes in differentiating HDSC and THESC}

Next, expression of decidual marker genes was analysed in untreated cultures and upon differentiation in the presence of cAMP or E2P4 using quantitative real-time PCR (Figure 4). PRL mRNA (Figure 4A) and IGFBP1 mRNA (Figure 4B) were strongly induced in HDSC upon cAMP treatment. However, this response was transient and highest levels of PRL and IGFBP1 transcripts were detected at 3 days of cAMP stimulation. Similarly, PRL mRNA (Figure 4A) and IGFBP1 mRNA
(Figure 4B) were induced in cAMP-treated THESC, but expression of both genes remained at high levels during differentiation. E2P4 treatment of HDSC provoked a steady increase of transcript levels of PRL (Figure 4A) and IGFBP1 (Figure 4B) which was significantly different to controls from day 3 (PRL) and day 6 (IGFBP1) onwards. In contrast neither PRL (Figure 4A) nor IGFBP1 (Figure 4B) mRNA were induced in THESC in the presence of E2P4. DKK1 has been recently described as a progesterone-dependent but cAMP-independent gene in decidualization [24]. Accordingly, E2P4 increased DKK1 mRNA expression in HDSC at day 3, 6, 9, and 12 of in vitro differentiation (Figure 4C). Compared to the respective controls, its expression was also induced upon cAMP treatment at 9 and 12 days of HDSC differentiation (Figure 4C). In THESC, however, DKK1 mRNA was not altered and suppressed in the presence of E2P4 and cAMP, respectively (Figure 4C). 


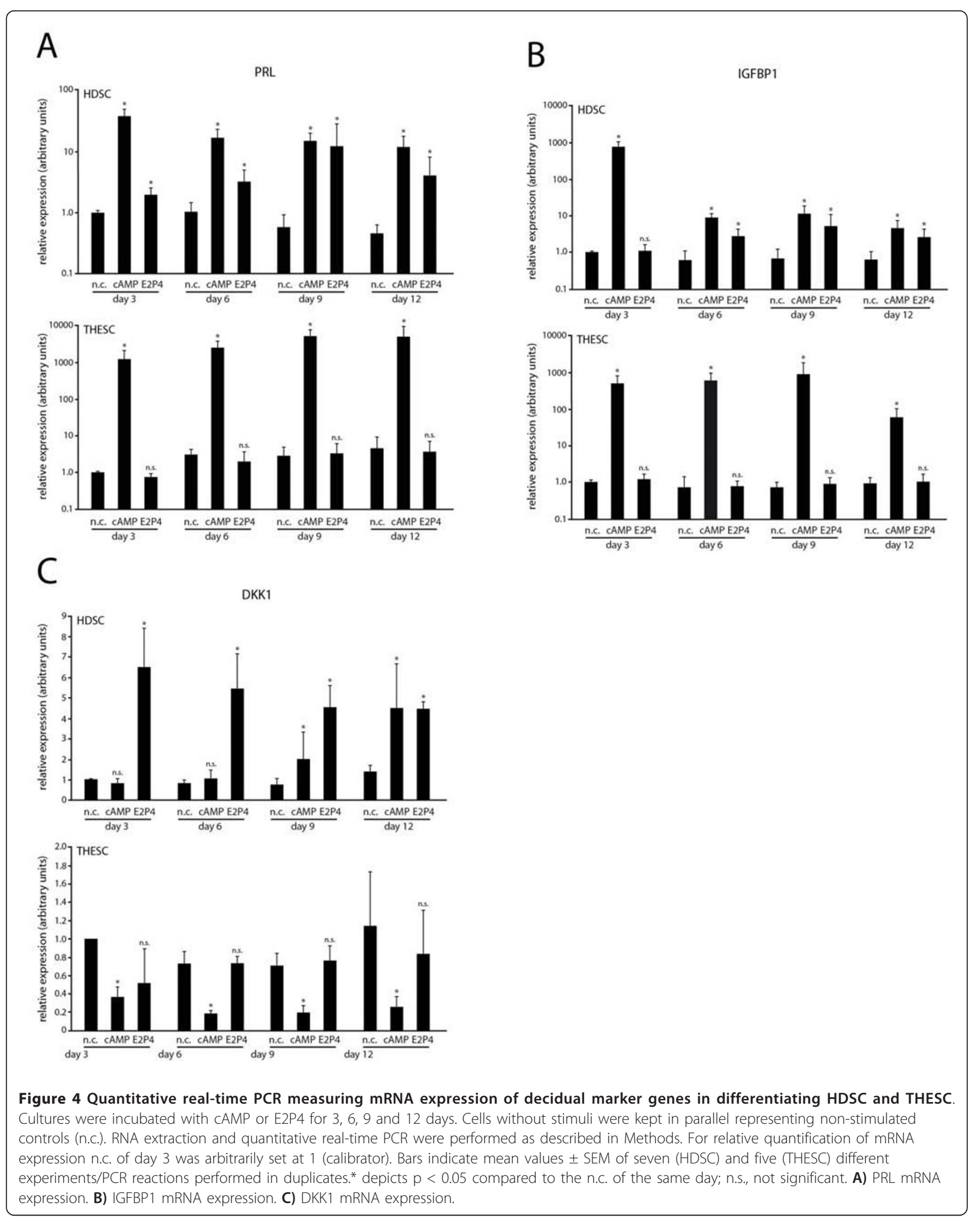


Moreover, the effects of a combined treatment with cAMP and E2P4 were analysed in HDSC and THESC (Figure 5). Real-time PCR of PRL (Figure 5A) and IGFBP1 (Figure 5B) mRNAs revealed that, compared to cAMP treatment alone, co-stimulation with cAMP and E2P4 further enhanced mRNA expression in HDSC. Increased mRNA expression of PRL (Figure 5A) and IGFBP1 (Figure 5B) was also detectable in THESC upon cAMP/E2P4 co-stimulation although the effects were less pronounced than in HDSC.

Subsequently, PRL and IGFBP1 protein expression were analysed in supernatants of HDSC and THESC using ELISA and Western blotting, respectively (Figure 6). Similar to its mRNA levels, PRL protein was induced upon cAMP or E2P4 stimulation of HDSC and expression further increased in the combined cAMP/E2P4 treatment (Figure 6A). PRL protein was also detectable in cAMP-treated THESC (Figure 6A) but absent from controls and E2P4-treated cells (not shown). Compared to cAMP alone, its expression increased upon supplementation of cAMP/E2P4. Soluble IGFBP1 protein also closely mimicked its mRNA expression under the different stimuli. Treatment of HDSC with cAMP provoked transient expression of IGFBP1 with highest levels at day 3, whereas in the presence of E2P4 the protein was detectable at day 9 and further increased at day 12 (Figure 6B). In cAMP-treated THESC high IGFBP1 levels were observed between day 6 and day 12, whereas the particular protein was absent from controls and E2P4-treated cultures (Figure 6B).

\section{Differentiation-dependent expression and localization of FOX01A in HDSC and THESC}

Finally, expression and localization of FOXO1A, a critical, transcriptional regulator of the decidualization-associated genes PRL and IGFBP-1 [12], were investigated (Figure 7). Western blot analyses revealed that cAMPincreased FOXO1A protein at all time points of differentiation in HDSC and THESC, whereas E2P4 did not change expression in both culture systems (Figure 7A). Immunofluorescence of cells revealed nuclear localization of FOXO1A upon cAMP stimulation (Figure 7B). In unstimulated cultures, however, FOXO1A was diffusely distributed within the cytoplasm (HDSC) or absent

\section{A}
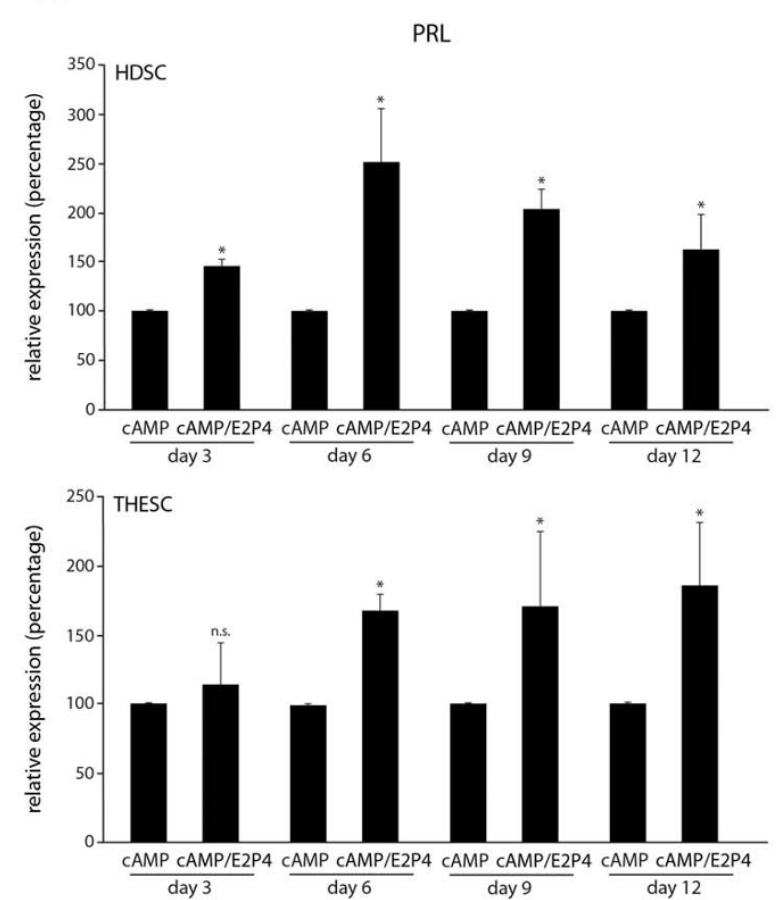

B
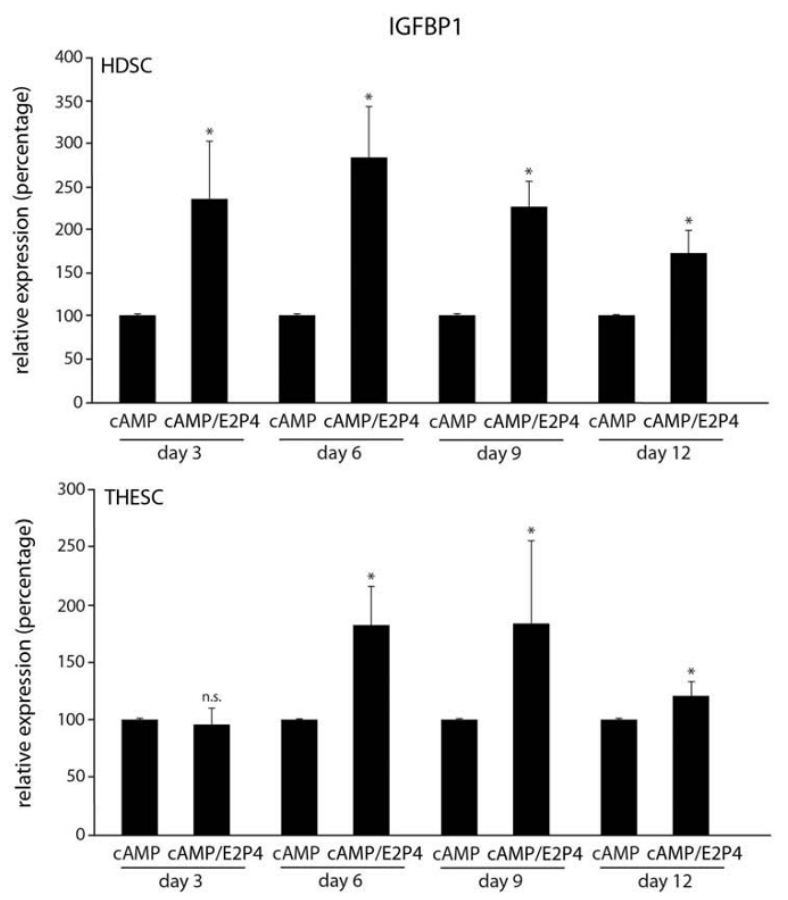

Figure 5 Quantitative mRNA expression of decidual marker genes upon cAMP stimulation or combined treatment with cAMP and E2P4 in differentiating HDSC and THESC. Cultures were incubated with E2P4 and/or CAMP for for 3, 6, 9 and 12 days and transcript levels were analysed by real-time PCR. For relative quantification of mRNA expression, CAMP-treated samples were arbitrarily set at 100\%. Bars indicate mean values \pm SEM of five and four different experiments performed in HESC and THESC, respectively. PCR reactions were done in duplicates. * indicates $p<0.05$ compared to the cAMP-stimulated sample of the same day; n.s., not significant. A) PRL mRNA expression. B) IGFBP1 mRNA expression. 


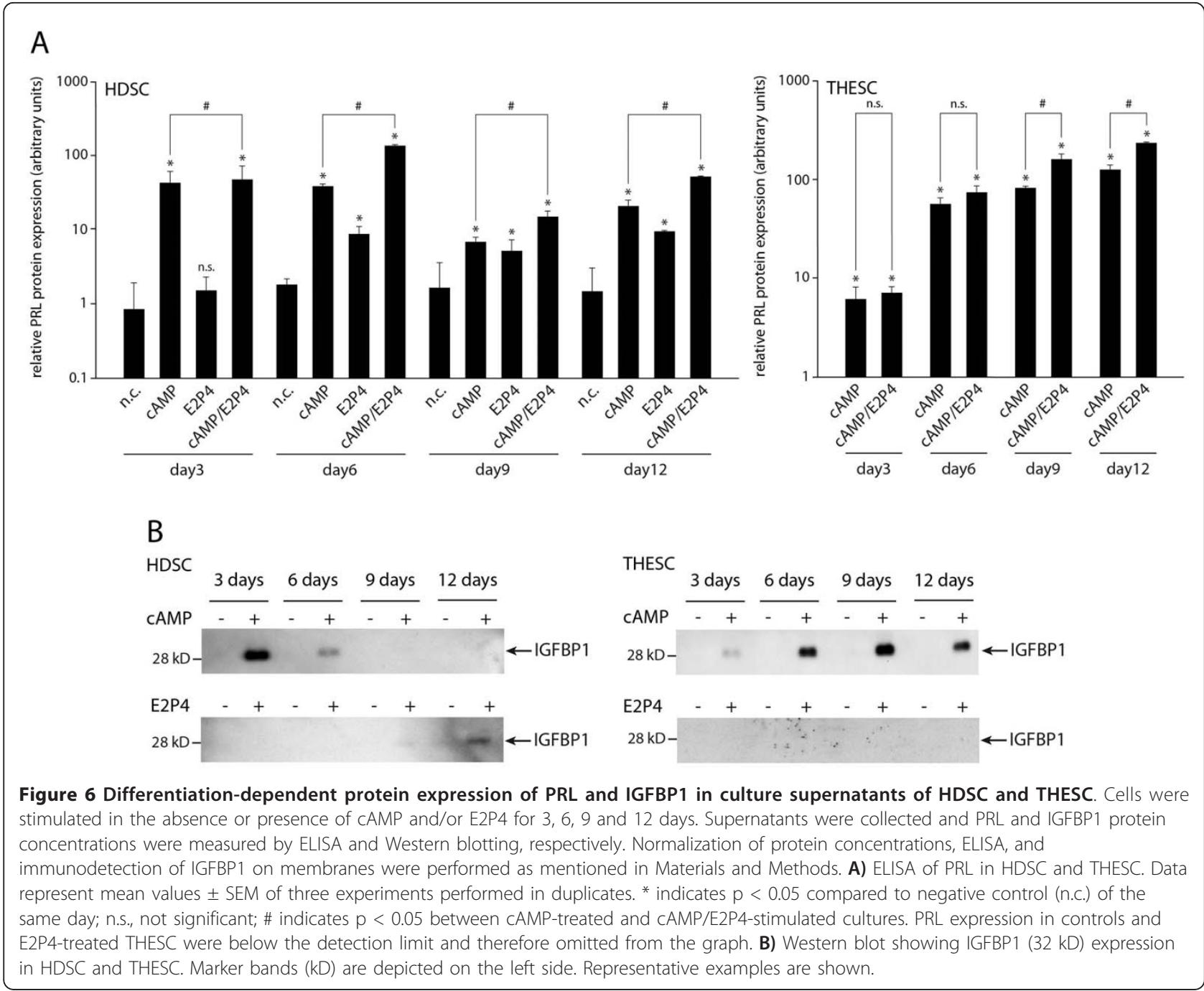

(THESC). Quantification of fluorescent images indicated an increase of FOXO1A-postive nuclei in both cell types upon cAMP treatment, whereas E2P4 was not effective (Figure 7C). Compared to cAMP stimulation, however, the combined cAMP/E2P4 treatment decreased numbers of FOXO1A-postive nuclei in HDSC, but not in THESC.

\section{Discussion}

Correct decidualization of the endometrium is indispensable for proper implantation, fetal development and successful progression of pregnancy. Hence, the underlying molecular mechanisms are critical to our understanding of implantation defects associated with infertility. Accordingly, in the recent years diverse in vivo animal models have been developed involving mouse and primate-systems $[25,26]$. In contrast to all other species, however, human decidualization starts spontaneously in the second half of the menstrual cycle in response to the predominating ovarian progesterone milieu. Therefore, adequate human in vitro models for decidualization had to be established and still comprise the basis to translate and verify results obtained from animal models. Indeed, HESC obtained from endometrial biopsies of pre-menopausal women or from uterine tissue after hysterectomy for benign gynaecological diseases are widely used for cAMP and/or E2P4 or MPAinduced in vitro differentiation $[12,14]$. However, availability of these samples might be limited, rising the need for alternative systems.

\section{Culture systems utilized for cAMP-dependent in vitro decidualization}

Therefore, efforts have been made to immortalize human endometrial stromal cells to overcome the restricted supply of primary HESC. Various immortalized cell lines were established after lentiviral transduction of plasmids expressing either SV40 large T antigen 


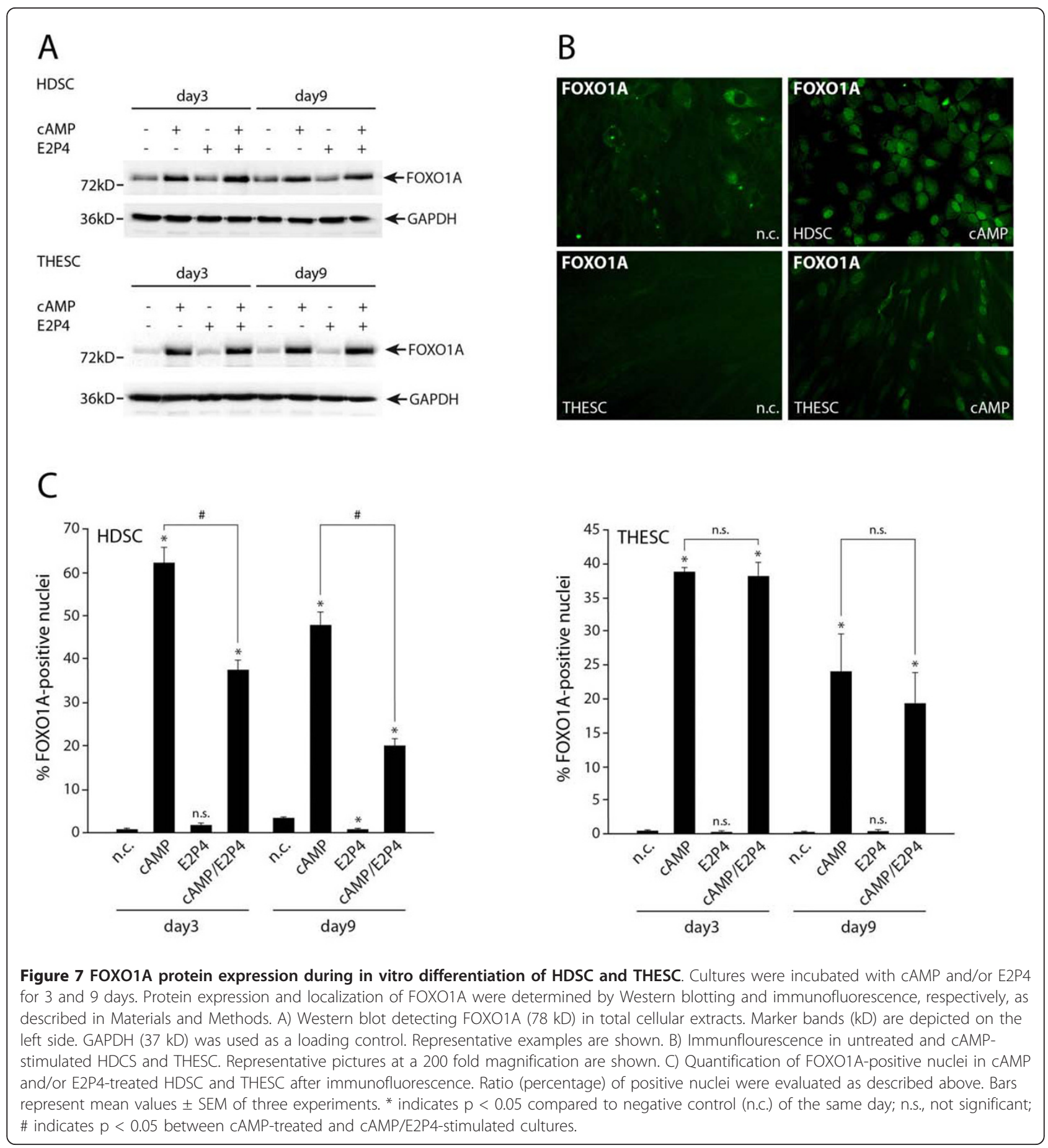

$[19,27,28]$ or telomerase $[20,29,30]$. In the presence of cAMP these cell lines were shown to differentiate into a cobblestone-like phenotype and to express marker genes of decidualization such as IGFBP1, PRL and FOXO1A [30]. The cAMP-dependent induction of PRL and IGFBP1 in THESC analysed here confirms these previous observations. Hence, it can be concluded that the cAMP-stimulated expression of markers genes might be similar in the immortalized cells and primary HESC suggesting suitability of cell lines for the particular differentiation protocol.

\section{The role of progesterone in in vitro decidualization}

On the other hand, it was suggested that cAMP may not be sufficient for maintenance of decidua-specific gene expression in differentiating primary HESC but requires 
the presence of progesterone [12]. Indeed, upon cAMP treatment MPA-dependent induction of PRL has been observed in HIESC-2 and St-TIb cultures [28,30] and similar to primary HESC [12] the combined stimulation was more efficient than cAMP treatment alone [30]. Moreover, MPA-induced expression of PRL and IGFBP1 in absence of cAMP has also been noticed in immortalized cultures [20,29] suggesting a physiological, PRdependent response. However, as has been recently pointed out MPA additionally interacts with glucocorticoid and androgen receptor [30], the latter being also involved in decidualization [31]. Therefore, a response to natural $\mathrm{P} 4$ rather than $\mathrm{MPA}$ and expression of $\mathrm{PR}$ as occurs in primary HESC could be regarded as a hallmark of physiological decidualization and cell identity. However, P4 responsiveness could not be detected in two different immortalized endometrial stromal cell lines $[18,19]$. Similarly, in THESC analysed here P4 did not affect expression of DKK1, a progesterone-inducible gene in HESC [24].

\section{Expression of progesterone receptors in different model systems of decidualization}

Analyses of PR protein expression in the different immortalized stromal cell lines such as THESC are either lacking [20] or unclear due to the fact that appropriate positive controls are missing $[28,29]$. Also, specificity of PR signals of a particular cell line [28] was questioned since the PR antibody used may show unspecific cross-reactivity [32]. The Western blot analyses performed here suggest that PRs are absent from THESC providing an explanation for the absence of $\mathrm{P} 4$ responsiveness. Although the PR antibody used in our study recognized two weak signals in nuclear extracts of THESC, these bands showed different molecular sizes than PR-A and PR-B produced in T47D cells. Differently to the regulation of PR in HDSC and primary HESC [13] the signals were not suppressed upon cAMP-induced differentiation. Therefore, we conclude that the antibody unspecifically recognizes a nuclear protein in THESC, particularly in the absence of PR protein. Interestingly THESC, like the previously described St-TIb cells [30], expressed considerable amounts of PR mRNA despite the absence of PR proteins. Moreover, combined treatment with cAMP and P4 of St-TIb [30] or of THESC provoked elevated PRL mRNA and protein expression compared to cAMP treatment alone. Considering the absence of nuclear $\mathrm{PR}$ protein in both cell lines activation through $\mathrm{P} 4$ remains elusive. Eventually, the effect might be explained by the non-genomic actions of progesterone [33].

\section{Human decidual stromal cells as an alternative model for in vitro decidualization}

An alternative for studying endometrial differentiation in untransformed cultures has been suggested by using isolated stromal cells from human term deciduas [34]. MPA - and cAMP-dependent induction of PRL and IGFBP1 was observed in these cultures reflecting the expression patterns observed in primary HESC. Furthermore, due to the strong similarities between HESC and term decidual stromal cells it was suggested that both cell types could be precursor decidual cells arising from the same cell lineage [34]. In the present study primary HDSC obtained from decidual tissue of early pregnancy terminations have been evaluated as a model system for in vitro differentiation. HDSC of early gestation develop in a progesterone-rich environment promoting differentiation. Indeed, at the time of isolation elevated basal levels of PRL and IGFBP1 were noticed which upon in vitro cultivation decreased in a passage-dependent manner. After a minimum of 3 passages basal marker gene expression of unstimulated cultures has sufficiently decreased to commence re-decidualization. Indeed, differentiated HESC also lose expression of decidua-specific genes upon withdrawal of stimuli [12]. Hence, we conclude that the absence of cAMP and progesterone promotes de-differentiation of HDSC, although the presence of residual progenitor cells in isolated cultures cannot be excluded. Indeed, recent evidence suggested that first trimester decidua contains spindle-shaped, multipotent decidual stromal cells capable of differentiating into diverse cell types including PRL-producing, differentiated decidual cells [35].

\section{Utilization of HDSC for CAMP or E2P4-induced in vitro decidualization}

Several lines of evidence presented here suggest that HDSC could provide an alternative model system to investigate cAMP and/or E2P4-dependent decidualization. In accordance with the published literature using HESC as model systems, HDSC had to be confluently seeded for proper differentiation. Experiments with cells at lower density revealed delayed induction of marker gene expression when stimulated with cAMP or E2P4 (unpublished observation). Despite slow proliferation due to contact inhibition, untreated cultures did not spontaneously differentiate as verified by constant basal levels of PRL and IGFBP1 mRNA during the entire stimulation period. The presence of cAMP, provoking changes in phenotype as well as growth arrest, resulted in rapid induction of marker genes of decidualization, $i$. e. PRL, IGFBP1 and FOXO1A. However, PRL and IGFBP1 mRNA and protein were transiently expressed and decreased at later time points of cAMP-stimulated differentiation. Similar observations have been published regarding PRL and IGFBP1 secretion in HESC $[12,13,36]$. Hence, we assume that similar to HESC cAMP treatment alone may not be sufficient for maintenance of decidual marker gene expression in HDSC. 
In contrast to cAMP, administration of E2P4 did not morphologically change HDSC but provoked a continuous increase of PRL and IGFBP1 transcript and protein levels. Indeed, it has been published that progestins also induce a steady but modest increase of PRL and IGFBP1 mRNA expression in HESC [37]. Interestingly, E2P4and cAMP-induced PRL protein levels were similar at day 9 of HDSC differentiation. In contrast, MPAinduced PRL concentrations at day 6 and 8 of HESC differentiation were shown to be approximately 1000 fold less than cAMP-induced levels [12,13]. From these observations we conclude that E2P4-dependent in vitro decidualization could be more efficient in HDSC than in HESC. This might be caused by higher endogenous levels of cAMP in untreated HDSC or a steeper increase in cAMP concentrations upon E2P4 treatment [15]. On the other hand cAMP, known to induce apoptosis in different culture systems $[38,39]$, provoked loss of HDSC after 6 days of incubation. Therefore, elevated endogenous cAMP levels in HDSC as compared to HESC could also provide an explanation for the higher sensitivity of these cells to the cell-damaging effects of exogenously added 8-Bromo-cAMP.

\section{Combined CAMP and E2P4 treatment of HDSC}

Compared to cAMP stimulation alone the combined treatment with cAMP and E2P4 further increased PRL and IGFBP1 mRNA expression and PRL protein levels in HDSC. Elevated expression of these genes might suggest that the combined treatment is necessary for complete and sustained marker expression and differentiation of HDSC as has been previously suggested for HESC $[12,13]$.

Along those lines, a natural progesterone response could be detected in HDSC since P4 increased mRNA levels of DKK1, which had been previously identified as a progesterone-inducible gene [24], at early and late time points of differentiation. In contrast to THESC, protein expression of PR-A and PR-B was detectable in isolated HDSC and both isoforms were downregulated upon cAMP treatment. These results are in agreement with studies performed in primary HESC triggered into differentiation with the particular stimulus [13]. Furthermore, PR-A is the dominant isoform expressed in HDSC mirroring the expression pattern observed both in human endometrium during the secretory phase in vivo as well as in isolated HESC in vitro $[13,40,41]$. Finally, compared to cAMP stimulation alone, combined treatment with cAMP and E2P4 decreased nuclear abundance of FOXO1A in HDSC indicating a hormonedependent effect. These data are agreement with previous observations in HESC [42] suggesting that progesterone could also promote survival of HDSC by reducing cAMP-dependent apoptosis mediated through
FOXO1A. Genomic actions of nuclear PRs likely play a role in cytoplasmic retention of FOXO1A since this phenomenon could not be observed in PR-deficient THESC.

\section{Conclusion}

Taken together, primary HDSC which were isolated from first trimester decidual tissue and treated with cAMP and/or E2P4 exhibit all features of correct decidualization known from studies performed with HESC as a model system. Even though single administration of cAMP longer than 6 days could not be recommended due to cell loss, short term differentiation proceeded correctly and mirrored expression patterns in HESC. E2P4 stimulation provoked continuous increases in marker gene expression suggesting that hormone-treatment of HDSC provides a suitable in vitro system to study human decidualization. Beside similar properties of HESC and HDSC upon differentiation, the usage of first trimester decidual tissues may eventually overcome the problem of limited availability of endometrial samples which can only be obtained when a benign gynaecological disease has been diagnosed. Regarding THESC as a model system cAMP-induced morphological transformation and marker gene expression can be achieved. However, P4-dependent differentiation may not be applicable due to the lack of physiological progesterone-responsiveness and the absence of classical PRs.

List of abbreviations

C/EPBB: CAAT enhancer binding protein $\beta$; CAMP: adenosine 3',5'-cyclic monophosphate; DKK1: Dickkopf-1; E2: 17ß-estradiol-acetate; ECM: extracellular matrix; ER: estrogen receptor; HESC: human endometrial stromal cells; HDSC: human decidual stromal cells; HUVEC: human umbilical vein endothelial cells; FOXO1A: forkhead box O1A; IGFBP1: insulin-like growth factor binding protein 1; IL: interleukin; HOX: homeobox; MPA:

medroxyprogesterone acetate; NK: natural killer; P4: 4-pregnene-3,20-dione; PBS: phosphate buffered saline; PRL: prolactin; PR: progesterone receptor; Stat: signal transducer and activator of transcription; THESC: telomerasetransformed endometrial stromal cells.

\section{Acknowledgements}

This study was supported by grant P-22687-B13 of the Austrian Science Funds to M. K.

\section{Author details}

Department of Obstetrics and Fetal-Maternal Medicine, Reproductive Biology Unit, Medical University of Vienna, A-1090 Vienna, Austria. ${ }^{2}$ Gynmed Clinic, A-1150 Vienna, Austria.

\section{Authors' contributions}

LS and GO performed all experiments presented in the manuscript such as primary cell culture, Western blot analyses and quantitative real-time PCR. JP helped with preparation of figures and draft on the manuscript. CF was responsible for isolation and delivery of first trimester decidual tissue. MK designed and coordinated the study and wrote the manuscript. All authors read and approved the final manuscript.

\section{Competing interests}

The authors declare that they have no competing interests. 
Received: 10 June 2011 Accepted: 7 December 2011

Published: 7 December 2011

\section{References}

1. Daly DC, Maslar IA, Riddick DH: Prolactin production during in vitro decidualization of proliferative endometrium. Am J Obstet Gynecol 1983, 145:672-678.

2. Lockwood CJ, Nemerson Y, Guller S, Krikun G, Alvarez M, Hausknecht V Gurpide E, Schatz F: Progestational regulation of human endometrial stromal cell tissue factor expression during decidualization. J Clin Endocrinol Metab 1993, 76:231-236.

3. Giudice LC, Dsupin BA, Irwin JC: Steroid and peptide regulation of insulinlike growth factor-binding proteins secreted by human endometrial stromal cells is dependent on stromal differentiation. J Clin Endocrinol Metab 1992, 75:1235-1241.

4. Dunn $\mathrm{CL}$, Critchley HO, Kelly RW: IL-15 regulation in human endometrial stromal cells. J Clin Endocrinol Metab 2002, 87:1898-1901.

5. Karpovich N, Klemmt P, Hwang JH, McVeigh JE, Heath JK, Barlow DH, Mardon HJ: The production of interleukin-11 and decidualization are compromised in endometrial stromal cells derived from patients with infertility. J Clin Endocrinol Metab 2005, 90:1607-1612.

6. Gellersen B, Brosens IA, Brosens JJ: Decidualization of the human endometrium: mechanisms, functions, and clinical perspectives. Semin Reprod Med 2007, 25:445-453.

7. Lash GE, Robson SC, Bulmer JN: Review: Functional role of uterine natural killer (uNK) cells in human early pregnancy decidua. Placenta 2010, 31(Suppl):S87-92.

8. Ramathal CY, Bagchi IC, Taylor RN, Bagchi MK: Endometrial decidualization: of mice and men. Semin Reprod Med 2010, 28:17-26.

9. Kim JJ, Jaffe RC, Fazleabas AT: Blastocyst invasion and the stromal response in primates. Hum Reprod 1999, 14(Suppl 2):45-55.

10. Kimatrai M, Oliver C, Abadia-Molina AC, Garcia-Pacheco JM, Olivares EG: Contractile activity of human decidual stromal cells. J Clin Endocrinol Metab 2003, 88:844-849.

11. Lim HJ, Wang H: Uterine disorders and pregnancy complications: insights from mouse models. J Clin Invest 2010, 120:1004-1015.

12. Gellersen B, Brosens J: Cyclic AMP and progesterone receptor cross-talk in human endometrium: a decidualizing affair. J Endocrinol 2003, 178:357-372.

13. Brosens JJ, Hayashi N, White JO: Progesterone receptor regulates decidual prolactin expression in differentiating human endometrial stromal cells. Endocrinology 1999, 140:4809-4820.

14. Brosens JJ, Gellersen B: Death or survival-progesterone-dependent cell fate decisions in the human endometrial stroma. J Mol Endocrinol 2006, 36:389-398.

15. Brar AK, Frank GR, Kessler CA, Cedars MI, Handwerger S: Progesteronedependent decidualization of the human endometrium is mediated by cAMP. Endocrine 1997, 6:301-307.

16. Gellersen B, Reimann K, Samalecos A, Aupers S, Bamberger AM: Invasiveness of human endometrial stromal cells is promoted by decidualization and by trophoblast-derived signals. Hum Reprod 2010, 25:862-873.

17. Menkhorst E, Salamonsen LA, Zhang J, Harrison CA, Gu J, Dimitriadis E: Interleukin 11 and activin A synergise to regulate progesterone-induced but not CAMP-induced decidualization. J Reprod Immunol 2010, 84:124-132.

18. Brosens JJ, Takeda S, Acevedo CH, Lewis MP, Kirby PL, Symes EK, Krausz T, Purohit A, Gellersen B, White JO: Human endometrial fibroblasts immortalized by simian virus 40 large $T$ antigen differentiate in response to a decidualization stimulus. Endocrinology 1996, 137:2225-2231.

19. Tamura K, Yoshie M, Hara T, Isaka K, Kogo H: Involvement of stathmin in proliferation and differentiation of immortalized human endometrial stromal cells. J Reprod Dev 2007, 53:525-533.

20. Krikun G, Mor G, Alvero A, Guller S, Schatz F, Sapi E, Rahman M, Caze R, Qumsiyeh M, Lockwood CJ: A novel immortalized human endometrial stromal cell line with normal progestational response. Endocrinology 2004, 145:2291-2296

21. Huber AV, Saleh L, Prast J, Haslinger P, Knofler M: Human chorionic gonadotrophin attenuates NF-kappaB activation and cytokine expression of endometriotic stromal cells. Mol Hum Reprod 2007, 13:595-604.

22. Sirover MA: New nuclear functions of the glycolytic protein, glyceraldehyde-3-phosphate dehydrogenase, in mammalian cells. J Cell Biochem 2005, 95:45-52.

23. Clemm DL, Sherman L, Boonyaratanakornkit V, Schrader WT, Weigel NL, Edwards DP: Differential hormone-dependent phosphorylation of progesterone receptor $\mathrm{A}$ and $\mathrm{B}$ forms revealed by a phosphoserine sitespecific monoclonal antibody. Mol Endocrinol 2000, 14:52-65.

24. Tulac S, Overgaard MT, Hamilton AE, Jumbe NL, Suchanek E, Giudice LC: Dickkopf-1, an inhibitor of Wnt signaling, is regulated by progesterone in human endometrial stromal cells. J Clin Endocrinol Metab 2006, 91:1453-1461.

25. Masuda H, Maruyama T, Hiratsu E, Yamane J, Iwanami A, Nagashima T, Ono M, Miyoshi $\mathrm{H}$, Okano HJ, Ito M, et al: Noninvasive and real-time assessment of reconstructed functional human endometrium in NOD/ SCID/gamma c(null) immunodeficient mice. Proc Natl Acad Sci USA 2007 104:1925-1930

26. Grummer R: Animal models in endometriosis research. Hum Reprod Update 2006, 12:641-649.

27. Brar AK, Kanda Y, Kessler CA, Cedars MI, Handwerger S: N5 endometrial stromal cell line: a model system to study decidual prolactin gene expression. In Vitro Cell Dev Biol Anim 1999, 35:150-154.

28. Chapdelaine P, Kang J, Boucher-Kovalik S, Caron N, Tremblay JP, Fortier MA: Decidualization and maintenance of a functional prostaglandin system in human endometrial cell lines following transformation with SV40 large T antigen. Mol Hum Reprod 2006, 12:309-319.

29. Barbier CS, Becker KA, Troester MA, Kaufman DG: Expression of exogenous human telomerase in cultures of endometrial stromal cells does not alter their hormone responsiveness. Biol Reprod 2005, 73:106-114.

30. Samalecos A, Reimann K, Wittmann S, Schulte HM, Brosens JJ, Bamberger AM, Gellersen B: Characterization of a novel telomeraseimmortalized human endometrial stromal cell line, St-T1b. Reprod Biol Endocrinol 2009, 7:76.

31. Cloke B, Huhtinen K, Fusi L, Kajihara T, Yliheikkila M, Ho KK, Teklenburg G, Lavery S, Jones MC, Trew G, et al: The androgen and progesterone receptors regulate distinct gene networks and cellular functions in decidualizing endometrium. Endocrinology 2008, 149:4462-4474.

32. Samalecos A, Gellersen B: Systematic expression analysis and antibody screening do not support the existence of naturally occurring progesterone receptor (PR)-C, PR-M, or other truncated PR isoforms. Endocrinology 2008, 149:5872-5887.

33. Gellersen B, Fernandes MS, Brosens JJ: Non-genomic progesterone actions in female reproduction. Hum Reprod Update 2009, 15:119-138.

34. Richards RG, Brar AK, Frank GR, Hartman SM, Jikihara H: Fibroblast cells from term human decidua closely resemble endometrial stromal cells: induction of prolactin and insulin-like growth factor binding protein-1 expression. Biol Reprod 1995, 52:609-615.

35. Dimitrov R, Kyurkchiev D, Timeva T, Yunakova M, Stamenova M, Shterev A, Kyurkchiev S: First-trimester human decidua contains a population of mesenchymal stem cells. Fertil Steril 2010, 93:210-219.

36. Gao JG, Mazella J, Tseng L: Activation of the human IGFBP-1 gene promoter by progestin and relaxin in primary culture of human endometrial stromal cells. Mol Cell Endocrinol 1994, 104:39-46.

37. Tseng L, Gao JG, Chen R, Zhu HH, Mazella J, Powell DR: Effect of progestin, antiprogestin, and relaxin on the accumulation of prolactin and insulinlike growth factor-binding protein-1 messenger ribonucleic acid in human endometrial stromal cells. Biol Reprod 1992, 47:441-450

38. Boe R, Gjertsen BT, Doskeland SO, Vintermyr OK: 8-Chloro-cAMP induces apoptotic cell death in a human mammary carcinoma cell (MCF-7) line. Br f Cancer 1995, 72:1151-1159.

39. Dowd DR, Miesfeld RL: Evidence that glucocorticoid- and cyclic AMPinduced apoptotic pathways in lymphocytes share distal events. Mol Cell Biol 1992, 12:3600-3608.

40. Mote PA, Balleine RL, McGowan EM, Clarke CL: Colocalization of progesterone receptors $\mathrm{A}$ and $\mathrm{B}$ by dual immunofluorescent histochemistry in human endometrium during the menstrual cycle. $J$ Clin Endocrinol Metab 1999, 84:2963-2971.

41. Mulac-Jericevic B, Conneely OM: Reproductive tissue selective actions of progesterone receptors. Reproduction 2004, 128:139-146. 
42. Labied S, Kajihara T, Madureira PA, Fusi L, Jones MC, Higham JM, Varshochi R, Francis JM, Zoumpoulidou G, Essafi A, et al: Progestins regulate the expression and activity of the forkhead transcription factor FOXO1 in differentiating human endometrium. Mol Endocrinol 2006, 20:35-44.

doi:10.1186/1477-7827-9-155

Cite this article as: Saleh et al: Evaluation of human first trimester decidual and telomerase-transformed endometrial stromal cells as model systems of in vitro decidualization. Reproductive Biology and Endocrinology 2011 9:155.

Submit your next manuscript to BioMed Central and take full advantage of:

- Convenient online submission

- Thorough peer review

- No space constraints or color figure charges

- Immediate publication on acceptance

- Inclusion in PubMed, CAS, Scopus and Google Scholar

- Research which is freely available for redistribution

Submit your manuscript at www.biomedcentral.com/submit 